\title{
Analysis of Lipase and Lipid Formation in Adipocytes Inhibitory Capabilities in Kelakai (Stenochlaena palustris) for Obesity Management
}

\author{
Maria D.P.T. Guanwan Puteri ${ }^{1, *}$, Filiana Santoso ${ }^{1}$, Evelyn Antoinette Halim ${ }^{1}$, \\ Della Rahmawati ${ }^{1}$, Eisuke Kato ${ }^{2}$, Yanetri Asi Nion ${ }^{3}$
}

${ }^{\text {I} D e p a r t m e n t ~ o f ~ F o o d ~ T e c h n o l o g y, ~ F a c u l t y ~ o f ~ L i f e ~ S c i e n c e s ~ a n d ~ T e c h n o l o g y, ~ S w i s s ~ G e r m a n ~ U n i v e r s i t y, ~ T a n g e r a n g, ~}$ Indonesia

${ }^{2}$ Laboratory of Food Science, Research Faculty of Agriculture, Hokkaido University, Sapporo, Japan

${ }^{3}$ Study Program of Agrotechnology, Department of Agriculture Palangkaraya University, Palangkaraya, Indonesia

*Corresponding author. Email: maria.gunawanputeri@sgu.ac.id

\begin{abstract}
The objective was to test $S$. palustris which has high antioxidant activity for bioactivities that may alleviate obesity: lipase inhibitory activity and lipid accumulated in 3T3-L1 adipocytes. Water, 50\% methanol and methanol extracts of S. palustris were tested for lipase inhibitory activity and lipid accumulation inhibition in 3T3-L1 adipocytes. For lipase inhibitory activity, the extracts and fractions with highest activity were separated and assayed again. Fractionation through column chromatography was done on the water extract to separate it into water, 50\% methanol and methanol fractions. The 50\% methanol and methanol fractions from the first column were fractionated again with a different column into water, $20 \%, 40 \%, 60 \%, 80 \%$ and methanol fractions. The result was the water extract showed the highest lipase inhibition while the methanol extract showed the highest lipid accumulation inhibition in adipocytes. In conclusion, S. palustris extracts with its lipase inhibitory activity as well as lipid accumulation in adipocytes suppression activity is promising for future research aimed at obesity management.
\end{abstract}

Keywords: S. palustris, obesity management, lipase, 3T3-L1 adipocytes, fractionation

\section{INTRODUCTION}

Obesity is a growing problem in an increasingly sedentary world. According to the WHO, 1.5 billion adults around the world are overweight and it is claiming lives [1]. In southeast Asia, the percentage of overweight adults has been increasing over the years with the same trend happening in Indonesia where the percentage increased from $14.8 \%$ to $21.8 \%$ in 5 years between 2013 and 2018 [2]. Obesity is a risk factor in developing many chronic diseases including diabetes type 2, coronary heart disease and stroke to name a few and is also indirectly a cause of mortality in adults worldwide. People with obesity are in a state of low-grade inflammation and oxidative stress due to the excess dietary calories being stored as visceral fat. This inflammation and oxidative stress are also thought to contribute to the pathogenesis of these obesity-related diseases. Obesity is also associated with lowered levels of specific antioxidants in the blood, thought to contribute to the emergence of the condition. However, the same research shows that supplementation with antioxidants may help alleviate the condition $[3,4]$.

Kelakai, with the scientific name Stenochlaena palustris, is one of the promising species being studied for its medicinal properties. It has been used traditionally as an antipyretic, antifungal and antibacterial by people in Indonesia, Malaysia, India and other countries [5]. It is also often consumed as a vegetable on the dining table. Previous research have shown high antioxidative activities of the plant extract with water in many of their parts from leaves to roots as well as in differing ages of the plant part from young to mature $[6,7]$ The same studies showed that $S$. palustris has high content of antioxidants and polyphenols, including kaempferol glycosides as well as hydroxycinnamic acids, which have strong antioxidative properties [8]. It is well known in traditional herbal medicine that plant materials, with high antioxidative effects, have a lot of potential as a herbal medicine $[9,10]$. The high antioxidative activity may mean that the plant could have components that are beneficial in managing obesity. This relation between antioxidative activity and lipid management bioactivities has not been explored. The same components responsible for antioxidant activity may also have lipid management capabilities.

Water extracts of $S$. palustris have been shown to have stronger antioxidative capabilities than ethanol extracts of the same plant. The IC50 for the ethanol extract is nearly twice that of water extract which means that the water extract is twice as good at scavenging free radicals as the ethanol extract. [11][12]. Water extraction is also 
convenient because it can be directly applied to foods and medicine as it is a safe and ubiquitous solvent. Especially in medicine or functional food applications, knowing what the bioactive compound is and how to best extract it is important as it can become a measurable standard to test and control the efficacy of the end product.

It is still unknown what the bioactive components of $S$. palustris maybe but the hydroxycinnamic acids, polyphenols as well as kaempferol glycosides present in $S$. palustris is a likely suspect $[6,13]$. This paper will hopefully shed some light on the relationship of its composition and the antioxidant activity of the extracts and find out if $S$. palustris also has lipid management potential through two tests targeting two pathways of fat gain, lipase inhibitiory activity which prevents triglycerides from being broken down and absorbed in the digestive system, and inhibtion of lipid accumulation in 3T3-L1 adipocytes, where excess glucose are metabolized and synthesized by adipocytes to produce triglycerides and stored.

$S$. palustris is a species of climbing fern that grows in many parts of southeast Asia. The Indonesian island of Kalimantan is one such place where this plant grows plentifully and is used in daily life as food. It is very easy to grow and during the year when this paper was written, none were being especially cultivated in Kalimantan. All the $S$. palustris available on the market is harvested from wild plants with no system of cultivation so the age of the individual plant is unknown. Also, since it has been used as food for generations, it is also quite safe to be consumed. However, the safety of the resultant extract is not yet tested.

The medicinal activity and thus the extraction of $S$. palustris has become the forefront of the research relating to the plant. Many combinations of extraction methods have been tried and researched on to best draw out the beneficial compounds within the plant itself. The most used extraction method is maceration in distilled water, due to the ease of the method and the antioxidative properties that are higher compared to extraction using less polar solvents like ethanol $[11,12]$. Many other papers used methanol to extract $S$. palustris with great yields possibly due to methanol's ambivalent properties. However, methanol which is also known as wood alcohol is also toxic when ingested by human beings and thus not ideal for use in food or medicine [6]. The young and mature fronds of the plant exhibit different activities and proportions of compounds as well $[8,14]$. These extracts of $S$. palustris have also been tested for its medicinal effects. They have been tested for antifungal and antibacterial activity, showing antimicrobial effects on 10 bacterial pathogens, one yeast species and four mold species in one paper [5]. Another paper proved similar in its conclusions [15]. The extracts have also been tested for its effects as an antipyretic by [9]. The extract was effective in reducing peroxidative stress in the liver of hoary marmots with induced fever. The non-polar extracts of $S$. palustris that contain sterols and fatty acids have also been found to demonstrate anti-cholinesterase activity which is thought to be beneficial to preventing Alzheimer's disease [6].
Other extraction solvents may need to be found if the extracts are to be ingested as alternatives to methanol and ethanol (for halal reasons) if these compounds are to be prioritized.

Many studies now link antioxidants with obesity, although the relationship between the two is still unclear. One study that reviewed antioxidant supplementation effects on people obesity concluded that supplementation with certain antioxidants (zinc, lipoic acid, carnitine, cinnamon and green tea) provides marginal but present benefits to manage the condition [4]. Another study correlates blood antioxidant levels and obesity levels and found that circulatory levels of antioxidants like carotenoids, vitamins $\mathrm{E}$ and $\mathrm{C}$, zinc, magnesium and selenium are lower in obese individuals. This suggests an inverse relationship between adiposity and blood antioxidant levels although the causality and the mechanism remain unclear [3].

For searching for the bioactive compound, fractionation is a good way to narrow down that responsible compound. Combined with bioassays, the fractions can be screened and in essence - the extract purified and the compound isolated. Column chromatography is until now, a relatively convenient and economic way to fractionate plant extracts and separate the constituents by polarity.

\section{METHODS}

$S$. palustris fronds were collected in bulk and at random from a single area in Kalimantan and transported back to Jakarta for post-harvest processing. The fronds were processed into a dry powder that will be used in subsequent extraction and analysis. The powder will be extracted with technical grade deionized water, ethanol, methanol and 50\% methanol. The water, methanol and $50 \%$ methanol extracts were evaluated with adipocyte lipid accumulation inhibition and lipase inhibition assay. Extracts with high activity were further separated and assayed again.

\section{a. Materials \& Equipment}

Fresh $S$. palustris fronds $(7.5 \mathrm{~kg}$ ) were collected from one location in Kalimantan. The collected fronds were around $30 \mathrm{~cm}$ long from the tip, bundled together with damp cotton around the stem bottom and packed into an insulated box with ice packs then transported by flight within 2 days back to Jakarta due to the ease at which they wilt. Right after arrival in Jakarta, the fronds were rinsed with running water, cleaned of debris, dried with paper towels, cut into sections with 2-3 leaves and frozen to preserve them. One complete sample of the fern was sent to a botanical institution (LIPI Biologi) for identification. The frozen fronds were then dried in batches at $50^{\circ} \mathrm{C}$ for 72 hours until their moisture content reached approximately $15 \%$. The dried leaves were then milled for $60 \mathrm{~s}$ and stored with desiccant to ensure dryness.

The dried powder was then extracted with four different solvents in a 1:20 ratio following the extraction method from Chai [8]. Deionized water, $96 \%$ ethanol, methanol and $50 \%$ methanol will be used, and both will be the technical grade for this usage. Maceration is done with a shaker and left to macerate for 1 day or 24 hours at room 
temperature. The extract was separated from the solids through a rough filtration with cheesecloth and centrifugation at $6000 \mathrm{rpm}$ in $50 \mathrm{ml}$ centrifuge tubes for the finer solids. The resultant solution had the solvents removed: the water extract through freeze-drying and the methanol $(\mathrm{MeOH})$ and $50 \%$ methanol $(50 \% \mathrm{MeOH})$ extract through the rotary evaporator (and subsequent freezedrying for the $50 \%$ methanol).

\section{b. Analytical method}

The extract with the higher lipase activity was then be partitioned using a column packed DIAION HP 20 adsorption beads and eluted with water, $50 \% \mathrm{MeOH}$ and finally $\mathrm{MeOH}$ in this order, resulting in water, $50 \% \mathrm{MeOH}$ and $\mathrm{MeOH}$ fractions. The ratio of packing to sample was 1 $\mathrm{g}$ of sample to $100 \mathrm{ml}$ of gel and the column of $4.5 \times 20 \mathrm{~cm}$ was eluted with three times the column volume, which is roughly $900 \mathrm{ml}$ per $300 \mathrm{ml}$ of gel. The fractions were concentrated in a rotary evaporator at $30^{\circ} \mathrm{C}$ and dried.

A subsequent fractionation was done on the fractions obtained from the DIAION HP20 column using a reversephase column. The packing was silica gel 120 (spherical) RP-18 (RP-18 gel) at a ratio of $1 \mathrm{ml}$ of gel per $10 \mathrm{mg}$ of sample. $300 \mathrm{mg}$ of the sample was partitioned with a $30 \mathrm{ml}$ column of diameter $1.5 \mathrm{~cm}$ and length $15 \mathrm{~cm}$. The column was eluted with three column volumes which is $90 \mathrm{ml}$ with the most polar water first followed by $20 \%, 40 \%, 60 \%$, $80 \% \mathrm{MeOH}$ and finally $\mathrm{MeOH}$. The resultant fractions were concentrated and dried in a rotary evaporator at $30^{\circ} \mathrm{C}$. Lipase Inhibition Assay - Lipase activity was emulated using a triolein lipid micelle emulsion and lipase solution. Tris- $\mathrm{HCl}$ buffer was prepared with the concentrations 13 $\mathrm{mM}$ tris- $\mathrm{HCl}, 150 \mathrm{mM} \mathrm{NaCl}$ and $3 \mathrm{mM} \mathrm{CaCl} 2$ and adjusted to $\mathrm{pH} 8.0$ with $1 \mathrm{~N} \mathrm{HCl}$. The micelle emulsion was made by first drying $200 \mu \mathrm{l}$ of $160 \mathrm{mg} / \mathrm{ml}$ triolein in chloroform solution and $200 \mu \mathrm{l}$ of $100 \mathrm{mg} / \mathrm{ml} \mathrm{L}-\alpha$-phosphatidylcholine in ethanol solution in the rotary evaporator at $30^{\circ} \mathrm{C}$ to remove the solvents. $10 \mathrm{mg}$ of sodium taurocholate and cold $9 \mathrm{ml}$ of tris- $\mathrm{HCl}$ buffer at $8.0 \mathrm{pH}$ was added and vortexed to mix evenly. The solution was sonicated on ice with the ultrasonic homogenizer for 5 mins with the settings duty cycle: constant, output control: 3. Lipase solution was prepared in tris- $\mathrm{HCl}$ buffer at $0.4 \mathrm{mg} / \mathrm{ml}$ concentration. Both lipase and micelle emulsion were prepared fresh every assay. $34 \mu \mathrm{M}$ of cetilstat in $50 \%$ DMSO was used as the positive control. The positive and negative control share the same blanks while for each sample, one sample blank was done.

Lipid Accumulation in Adipocytes Inhibition Assay Extracts from S. palustris dissolved in 50\% DMSO were tested at $1,0.5$ and $0.1 \mathrm{mg} / \mathrm{ml}$ final concentrations. $350 \mu \mathrm{l}$ of the micelle emulsion and $100 \mu \mathrm{l}$ of the sample was preincubated at $37^{\circ} \mathrm{C}$ with mixing at $1200 \mathrm{rpm}$ for 5 minutes in the Thermomixer ${ }^{\circledR}$. After incubation, $50 \mu$ of lipase solution was added and it was incubated with the above conditions for 20 minutes, after which $50 \mu \mathrm{l}$ of stop solution $(1 \mathrm{~N} \mathrm{HCl})$ is added to halt the reactions. The mixture was mixed with the same thermomixer at $1200 \mathrm{rpm}$ for 30 seconds to homogenize.
The reacted mixture was extracted with $600 \mu$ of n-hexane and agitated for 3 minutes with an intellimixer then left to settle for 1 minute. $300 \mu \mathrm{l}$ of the hexane extract was taken and dried in a rotary evaporator at $40^{\circ} \mathrm{C}$ for 45 minutes. The dried extract was dissolved in $100 \mu \mathrm{l}$ DMSO and sonicated for 30 minutes.

The resulting DMSO solution is assayed with NEFA C test kit. $8 \mu \mathrm{l}$ of the sample was mixed with $80 \mu \mathrm{l}$ of $12 \mathrm{mg} / \mathrm{ml}$ solution A and incubated for 10 minutes at $37 \mu \mathrm{C} .160 \mu \mathrm{l}$ of $5 \mathrm{mg} / \mathrm{ml}$ Solution B was added and it is again incubated for 10 minutes at the same temperature before measuring the absorbance of the purple resultant color at $550 \mathrm{~nm}$.

The inhibition of lipase by the samples is calculated by the equation below.

$$
\begin{gathered}
\% \text { inhibition }= \\
100 *\left(1-\frac{\text { sample absorbance }- \text { sample blank absorbance }}{\text { average absorbance of }(\text { control }- \text { blank })}\right)
\end{gathered}
$$

$0.2 \mathrm{mg} / \mathrm{ml}$ solutions in $50 \%$ DMSO were made of the fractionation results that were separated from the extracts and fractions with the highest activity and tested in the same way for lipase inhibitory activity.

3T3-L1 pre-adipocytes were seeded into 48-well plates with $250 \mu \mathrm{l} 10 \%$ FBS, $90 \mu \mathrm{g} / \mathrm{ml}$ streptomycin, $45 \mu \mathrm{g} / \mathrm{ml}$ gentamycin and $90 \mathrm{U} / \mathrm{ml}$ penicillin supplemented high glucose DMEM (referred to $10 \%$ FBS/DMEM) medium per well. One day after confluency, day 3, the cells were differentiated with the same $10 \% \mathrm{FBS} / \mathrm{DMEM}$ supplemented with $0.5 \mathrm{mM}$ IBMX, $0.25 \mu \mathrm{M}$ DEX, $5 \mu \mathrm{g} / \mathrm{ml}$ insulin. Two days after the addition of the differentiation medium, the medium was exchanged with $5 \mu \mathrm{g} / \mathrm{ml}$ insulin supplemented $10 \%$ FBS/DMEM to enhance differentiation. On day 4 , the medium is exchanged for the same insulin supplemented medium that contains samples in $50 \%$ DMSO diluted to concentrations of $1,0.8,0.5,0.3,0.1$, $0.05 \mathrm{mg} / \mathrm{ml}$. The end DMSO content in the medium is $0.5 \%$. On day 6 , the plate is refreshed with $10 \% \mathrm{FBS} / \mathrm{DMEM}$ supplemented with the samples at the same concentrations as on day 4 .

On day 9 the plate is ready for the Adipored ${ }^{\mathrm{TM}}$ assay. All remaining medium is aspirated out and washed with $0.4 \mathrm{ml}$ PBS. $0.4 \mathrm{ml}$ PBS and $12 \mu \mathrm{l}$ of Adipored ${ }^{\mathrm{TM}}$ was added to each well mixed with $0.4 \mathrm{ml}$ PBS, incubated for 10-13 minutes at room temperature and the fluorescence with excitation at $485 \mathrm{~nm}$ and emission at $572 \mathrm{~nm}$ was read with the microplate reader.

The lipid accumulation in adipocytes is quantified using the equation below.

$$
\begin{gathered}
\text { \% lipid accumulation }= \\
\text { average absorbance of treatment }
\end{gathered}
$$

Cell Viability Assay - A plate treated the same way as in the lipid accumulation assay is made and on day 9 , the well contents are changed to $10 \%$ of $\mathrm{CCK}-8$ solution supplemented 10\%FBS/DMEM medium and incubated for three hours. For pre-adipocytes, a 48 well plate is seeded and allowed to grow to confluency in 3 days. The cells are then exposed to the samples at $1,0.8$ and $0.5 \mathrm{mg} / \mathrm{ml}$ concentrations in $10 \% \mathrm{FBS} / \mathrm{DMEM}$ for 24 hours. The medium is also changed to $10 \%$ CCK- 8 solution 
supplemented $10 \% \mathrm{FBS} / \mathrm{DMEM}$. $1 \%$ TX-100 was used as the positive control and is added at the same time as CCK-8 solution to one set of wells. After three hours incubation, $10 \mu \mathrm{l}$ of the supernatant is taken and added to $80 \mu \mathrm{l}$ of Milli-Q ${ }^{\circledR}$ then read at $450 \mathrm{~nm}$ in the microplate reader. Remaining live and viable cells were calculated according to the equation below.

$$
\% \text { cells alive }=100 \times \frac{\text { average absorbance of treatment }}{\text { average absorbance of control }}
$$

ANOVA one factor and two-factor calculations were generated using Real Statistics to analyze lipase inhibitory data. Tukey HSD post-hoc analysis was done after both one and two factors ANOVA. Levene's test was conducted on the raw data before the one-way ANOVA.

Paired student t-test was used to compare populations of control to treatment for lipid accumulation in adipocyte and cytotoxicity assays.

p-value used to evaluate the statistics was alpha $=0.05$

\section{RESULTS AND DISCUSSION}

\section{a. Lipase Inhibition}

Between the raw extracts tested (water, $50 \% \mathrm{MeOH}$ and $\mathrm{MeOH}$ ), lipase inhibitory activity is found to be highest in the water extract (figure 1). The efficacy at $1 \mathrm{mg} / \mathrm{ml}$ and 0.5 $\mathrm{mg} / \mathrm{ml}$ rivals that of $34 \mu \mathrm{M}$ cetilstat in the positive control, which is a lipase inhibitor drug on the market used to manage obesity.

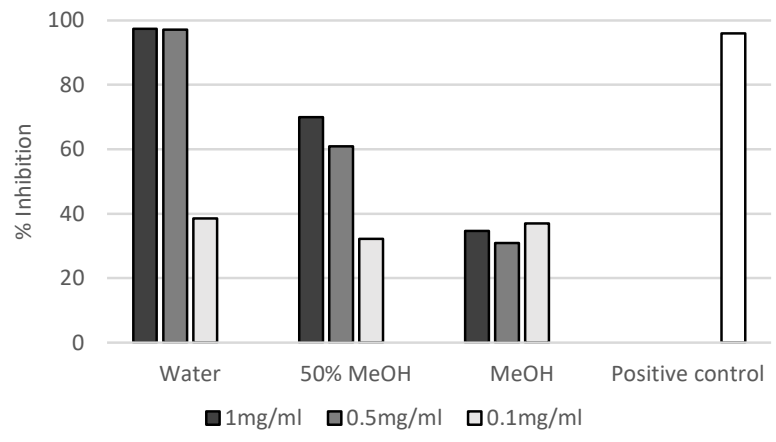

Figure 1. Lipase inhibition activity expressed as percent inhibition in water, methanol and $50 \%$ methanol extracts at different concentrations.

2-way ANOVA with replication was used to determine the statistical significance of the results and disprove the null hypothesis that there is no difference in means. The effect of solvent choice as well as concentration was found to be significant on lipase inhibition with p-values below 0.05 . No interaction between the two factors (solvent and concentration), was found through this statistical test. Tukey HSD was used to determine where the differences in means lie and it was found that 0.1 against $1 \mathrm{mg} / \mathrm{ml}$ concentrations as well as water against $\mathrm{MeOH}$ solvent groups are significantly different.

Further fractionation of the water extract into three fractions (water, $50 \% \mathrm{MeOH}$ and $\mathrm{MeOH}$ ) using the DIAION HP20 gel and testing of these three fractions was done as shown in figure 2 . The fraction with the highest lipase inhibitory activity is the $\mathrm{MeOH}$ fraction with $45.2 \%$ inhibition while the other two fractions have very little to no activity at all. One factor ANOVA as well as Tukey HSD was used to compare the fractions and all three are significantly different from each other.

Despite originating from a very polar extract, namely the water extract, it is instead the least polar fraction that exhibits the highest activity. The polarity of the bioactive compound may have a polarity in between that of water and methanol since the initial methanol extract does not exhibit high lipase inhibitory activity.

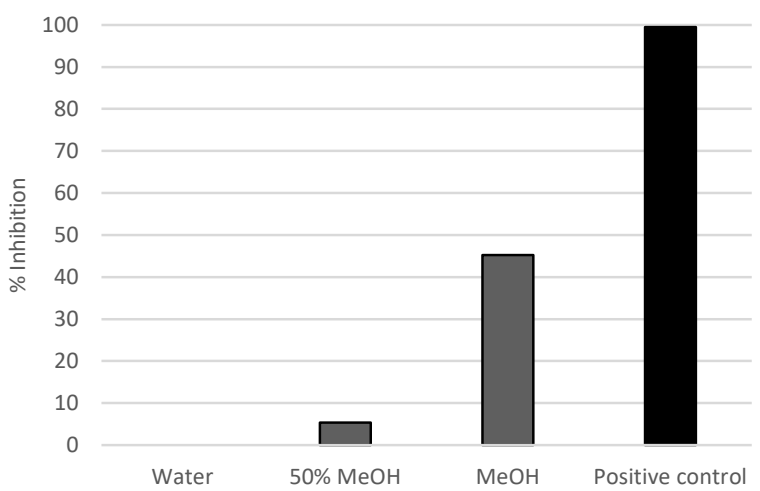

Figure 2. inhibition activity expressed as percent inhibition of the three fractions (water, $50 \% \mathrm{MeOH}$ and $\mathrm{MeOH}$ ) separated from water extract and the positive control.

Since only the $50 \% \mathrm{MeOH}$ and $\mathrm{MeOH}$ fractions exhibited any lipase inhibitory activity, further fractionation was performed on these two fractions. The measured lipase inhibitory activities were measured (figure 3). The initial $50 \% \mathrm{MeOH}$ and $\mathrm{MeOH}$ fractions (DIAION) were subdivided by reverse phase column (RP-18) into the most polar water fraction, then $20 \%, 40 \%, 60 \%, 80 \%$ and $\mathrm{MeOH}$ fractions. Lipase inhibition was highest in the $\mathrm{MeOH}$ fraction (RP-18) obtained from the $\mathrm{MeOH}$ fraction (DIAION) at $69.8 \%$ inhibition.

One way ANOVA and post-hoc t-test was done on the data to ensure that the null hypothesis (that there is no difference in means) is not true and to determine where the differences lie. The one way ANOVA results show that for the RP-18 fractions of both DIAION fractions, the effect of the factor (fraction) is significant on the differences seen in the data. The source of the significance in the $50 \% \mathrm{MeOH}$ fraction (DIAION) fractionation products were the water fraction against the $20 \%$ and $40 \% \mathrm{MeOH}$ fractions, and the $\mathrm{MeOH}$ fraction against the $20 \%$ and $40 \% \mathrm{MeOH}$ fractions (letter pairings abcde are used to show the relationship in figure 3 below). In the $\mathrm{MeOH}$ fraction (DIAION) fractionation products, the differences were found between all fractions except the $20 \% \mathrm{MeOH}$ against $40 \%$ and $60 \% \mathrm{MeOH}$ fractions, and the $40 \% \mathrm{MeOH}$ fraction against $60 \% \mathrm{MeOH}$ fractions (strikethrough letter pairings $\mathrm{ABC}$ are used to show where significance was not seen). 


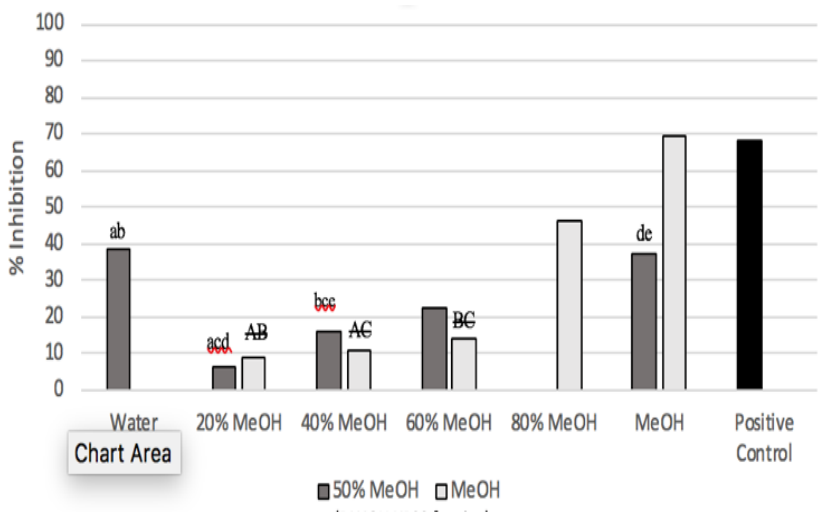

Figure 3. Lipase activity in the water, $20 \%, 40 \%, 60 \%$, $80 \%$ and $\mathrm{MeOH}$ fractions (RP-18) obtained from the $50 \%$ $\mathrm{MeOH}$ and $\mathrm{MeOH}$ fractions (DIAION). Samples were tested at $0.2 \mathrm{mg} / \mathrm{ml}$ concentrations and positive control is Cetilstat at $34 \mu \mathrm{M}$

\section{b. Lipid Accumulation in 3T3-L1 Adipocytes Inhibition}

All three extracts from S. palustris showed lipid accumulation suppression after 3T3-L1 Adipocytes were exposed to the extracts between day 4-9 (figure 4). The treatment groups were compared to the control group (blank) using the paired student t-test to ensure that the populations are significantly different. For the highest concentration tested, all measurements were significantly lower than that of control when tested against $p$-value 0.05 however the water extract at lower concentrations showed more variation and cannot be considered statistically significant. Both the $\mathrm{MeOH}$ and water extracts show more activity with increased concentration of the exposed extract while the $50 \% \mathrm{MeOH}$ extract does not show the same behaviour. The highest activity was shown in the $\mathrm{MeOH}$ extract, second strongest is water and third is $50 \%$ $\mathrm{MeOH}$ at the highest tested concentration. Due to the fact that obesity is a complex process since the number of adipocytes as well as amount of lipid produced can both affect the end amount of fat that accumulates in the cell, this assay is limited in the fact that it only measures the end total amount of fat accumulated and not how the extracts are exerting their effects.

While the exact way the lipid accumulation in 3T3-L1 adipocytes cannot be elucidated, a simple cell cytotoxicity assay can show if cell deaths were the reason. When mature adipocytes were exposed to the $\mathrm{MeOH}$ extract from day 4 to day 9 , slight dose-dependant cytotoxicity was seen as shown in figure 5 . At the highest concentration, around $80 \%$ of the cells survived. Due to time constraints during the research period, only the methanol extract which exhibited the highest lipid accumulation inhibition activity was assayed with conditions replicating the lipid accumulation assay.

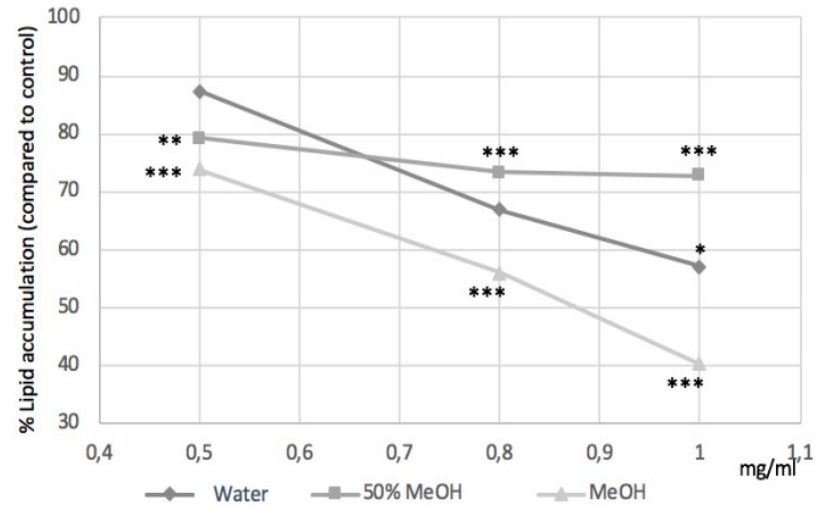

Figure 4. Lipid accumulation as a percentage of control of mature adipocytes exposed to water, $50 \%$ methanol and methanol extracts at different concentrations $(* * * p<0.001$,

$* * \mathrm{p}<0.01$ and $* \mathrm{p}<0.05$ when compared to control with student t-test comparison of means)

The other two extracts' cytotoxicity was checked in tandem with the original $\mathrm{MeOH}$ extract using preadipocytes - chosen due to the speed at which the assay can be completed. After 24 hour exposure to the samples at differing concentrations, no cytotoxicity can be seen in all the samples as shown in figure 6 . In fact, the cell viability ratio is much higher in the $50 \% \mathrm{MeOH}$ extract and slightly higher in the $\mathrm{MeOH}$ extract. The water extract exposed sample was indistinguishable from the control. The differences in the physiology and the metabolism of the pre-adipocytes and the mature adipocytes along with the mechanism at which the active constituent of the extracts worked may be the reason this discrepancy resulted. Due to the method at which CCK-8 determines cell viability through pyruvate metabolism, compounds that boost this metabolism may also cause the absorbance to be higher to the actual living cell count. For future research, more than one type of cell viability method may be employed to determine the actual cell viability ratio.

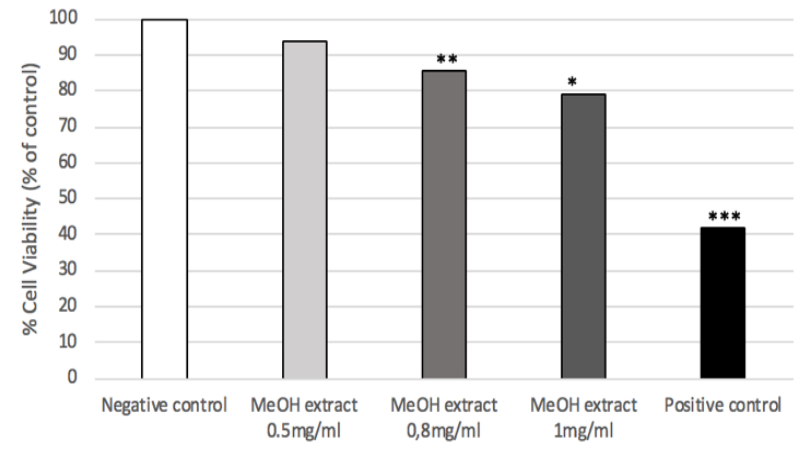

Figure 5. Cytotoxicity assay with CCK-8 kit on mature 3T3-L1 adipocytes exposed to methanol extract from day 4-9 with triton- $X$ cell lysing agent as positive control $(* * * p<0.001, * * p<0.01$ and $* p<0.05$ when compared to control with student t-test comparison of means) 


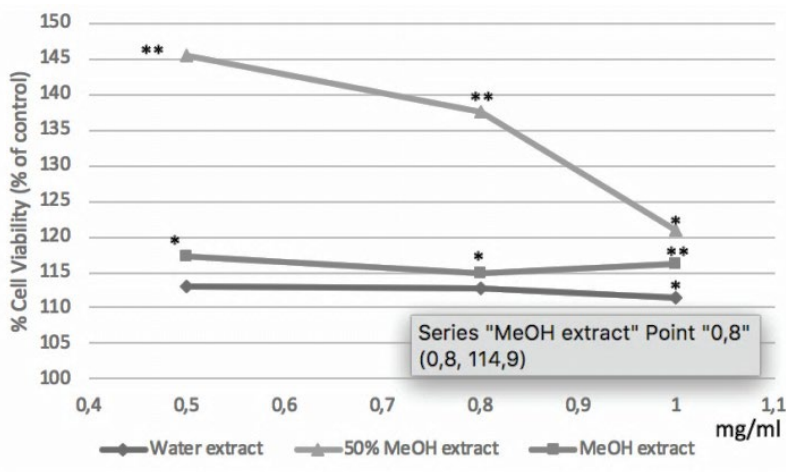

Figure 6. Cytotoxicity assay with CCK-8 on confluent 3T3-L1 pre-adipocytes ( 3 days after seeding) after exposure to samples for 24 hours $(* * * p<0.001, * * p<0.01$ and $* \mathrm{p}<0.05$ when compared to control with student t-test comparison of means)

\section{CONCLUSION}

S. palustris extracts that were tested on the lipid related bioassays show activity. All extracts showed some activity in both lipase inhibition and lipid accumulation inhibition but lipase activity is highest in the water extract while the $\mathrm{MeOH}$ extract displayed the highest activity for suppression of lipid accumulation in adipocytes. Cytotoxicity studies show that the extracts are not cytotoxic in the pre-adipocyte CCK- 8 assay but conflictingly in mature adipocytes, methanol extract shows slight cytotoxicity. Further fractionation and assay of the water extract revealed that the $\mathrm{MeOH}$ fraction of the $\mathrm{MeOH}$ fraction displayed the highest lipase inhibitory activity.

\section{ACKNOWLEDGMENT}

I wish to thank my advisor and co-advisor, Maria Gunawan Puteri of Swiss German University and Eisuke Kato of Hokkaido University for their support and guidance from the beginning. I would also like to thank JASSO and Hokkaido University for the opportunity to pursue my research in Japan.

\section{REFERENCES}

[1] WHO. Obesity and overweight [Internet]. World Heal. Organ. 2018 [cited 2019 Jun 20]. Available from: https://www.who.int/news-room/factsheets/detail/obesity-and-overweight

[2] Kemenkes. Potret Sehat Indonesia dari Riskesdas 2018 [Internet]. Kementeri. Kesehat. Republik Indones. 2018 [cited 2019 Jun 20]. Available from: http://www.depkes.go.id/article/view/18110200003/ potret-sehat-indonesia-dari-riskesdas-2018.html

[3] Hosseini B, Saedisomeolia A, Allman-farinelli M. Association Between Antioxidant Intake / Status and Obesity: a Systematic Review of Observational Studies. Biol Trace Elem Res [Internet]. Biological Trace Element Research; 2016; Available from: http://dx.doi.org/10.1007/s12011-016-0785-1

[4] Abdali D, Samson SE, Kumar A. How Effective Are Antioxidant Supplements in Obesity and Diabetes? 2015;201-15.

[5] Zuraini Z, Sasidharan S, Kaur SR, Nithiyayini M, Pinang P. Newsletter Antimicrobial and Antifungal Activities of Local Edible Fern Stenochlaena Palustris ( Burm . F .) Bedd Newsletter Zuraini et al . 2010;237:233-7.

[6] Chear NJY, Khaw KY, Murugaiyah V, Lai CS. Cholinesterase inhibitory activity and chemical constituents of Stenochlaena palustris fronds at two different stages of maturity. J Food Drug Anal [Internet]. Elsevier Ltd; 2016;24:358-66. Available from: http://dx.doi.org/10.1016/j.jfda.2015.12.005

[7] Kusmardiyani S, Novita G, Fidrianny I. Antioxidant Activities From Various Extracts of Different Parts of Kelakai ( Stenochlaena Palustris ) Grown in Central Kalimantan - Indonesia. Asian J Pharm Clin Res. 2016;9:215-9.

[8] Chai TT, Panirchellvum E, Ong HC, Wong FC. Phenolic contents and antioxidant properties of Stenochlaena palustris, an edible medicinal fern. Bot Stud. 2012;53:439-46.

[9] Suhartono E. Stenochlaena palustris aqueous extract reduces hepatic peroxidative stress in Marmota caligata with induced fever. Universa Med. 2010;29:123-8.

[10] Chabib L, Muhtadi WK, Rizki MI, Rahman RA, Suhendri MR, Hidayat A. Potential medicinal plants for improve the immune system from Borneo Island and the prospect to be developed as nanomedicine. MATEC Web Conf. 2018. p. 4006.

[11] Wijaya E, Widiputri DI, Rahmawati D. Optimizing the antioxidant activity of Kelakai (Stenochlaena palustris) through multiplestage extraction process. AIP Conf Proc. 2017.

[12] Rahmawati D, Rifky NA, Marpaung AM. palustris IPSFAB-2017 Extraction and stability analysis of antioxidant activity from Stenochlaena palustris. 2017;

[13] Moresby P. Glycosides from stenochlaena palustris phytochemistry.pdf. 1998;49:0-5.

[14] Dash GK, Syahirah Z, Mohd B. Pharmacognostic studies on Stenochlaena palustris ( Burm . f) Bedd. 2016;8:132-7.

[15] Ponnusamy Y, Chear NJY, Ramanathan S, Murugaiyah V, Lai C-S. Antioxidant and antibacterial properties of Malaysian ferns used traditionally against infection. J Nat Prod Plant Resourse. 2013;3:14-8.

[16] Altemimi A, Lakhssassi N, Baharlouei A, Watson DG. Phytochemicals: Extraction, Isolation, and Identification of Bioactive Compounds from Plant Extracts. Plants by MDPI. 2017;6. 